\title{
DIFFERENCES IN THE NATIONAL HEALTH SERVICES OF ENGLAND AND SCOTLAND
}

\author{
BY \\ I. A. G. MACQUEEN \\ Health and Welfare Department, City of Aberdeen
}

It is strictly incorrect to say that there is a National Health Service in the United Kingdom. There are three separate services, covering respectively England and Wales, Scotland, and Northern Ireland. While broadly similar, the three vary in quite a number of points. The present article is an attempt to indicate the main particulars in which the service in Scotland differs from that in England, to explain why these variations came into being, and to discuss possible results accruing from them.

GeOgraPhical FaCtors.-Scotland comprises onethird of the territory of Britain and contains only one-ninth of the population; by English standards, large tracts are almost uninhabited. If on a map you draw a line slanting from the mouth of the Clyde to the Firth of Tay and then turning at right angles to pass up to the Moray Firth, and a second line (parallel to the first portion of the other) from Ayr to Dunbar, you will have divided Scotland into four zones. The narrow belt in the middle - the Central Lowlands-holds over $3 \frac{1}{2}$ million persons in some 4,000 square miles (i.e. it corresponds to an English hospital region of average size and more than average density); the North-Eastern triangle contains 750,000 people in 4,500 square miles (i.e. it is a shade larger than Devon and Cornwall but less thickly populated) and the population density in most of the triangle is even less than would appear from the figures, because half the inhabitants live in the cities of Dundee and Aberdeen; the Southern Uplands extend over 5,000 square miles of hill country and have 300,000 inhabitants (a sparsity far beyond anything found in England); and the beautiful but desolate north - the Highlands and Islands-stretches over 16,500 square miles but contains only 400,000 people (i.e. it covers an area as large as one-third of England but has a population rather greater than Cumberland or rather less than Somerset).

The geographical configuration made it impracticable to have less than five hospital regions in
Scotland, and determined that three of the regions should serve populations of very restricted size. The Western Hospital Region (based on Glasgow and extending from Argyll to the Solway) and the South-Eastern based on Edinburgh and stretching from Fife to the Border) resemble English regions, but the North-Eastern (based on Aberdeen) serves 500,000 persons, the Eastern (based on Dundee) only 400,000 , and the Northern (based on Inverness) - the one region without a University-under 200,000. These regions may serve as a yard-stick to measure whether (as is often alleged) regions containing several million people are too large.

Again, in the development of Local Health Authority services in England, towns with populations of $50,000-200,000$ tended to play a leading part: one has only to think, for example, of county boroughs like Ipswich, Reading, Middlesbrough, Barnsley, and Carlisle, or even of large non-county boroughs like Stockton-on-Tees, Luton, Cambridge, Mansfield, and Swindon. Scotland, however, has only seven burghs of over 50,000 inhabitants-the four main cities, and Paisley, Greenock, and Motherwell. Similarly, while English administrative counties with under 75,000 inhabitants are rare, in Scotland most counties have populations below that figure and none is so populous as to require delegation of health or education functions to divisional authorities. The populations of most of the Scottish Local Health Authorities are so small that it was deemed impracticable to place on them responsibility for the provision of health centres and ambulance services: for both of these responsibility has remained with the Secretary of State for Scotland, although in the case of the ambulance service the duty has been delegated to the Regional Hospital Boards.

The small populations served by Scottish Local Authorities also afford an explanation why the areas of Executive Councils in Scotland do not always coincide with those of Local Health Authorities: there are 55 of the latter (although, through joint 
appointments in a few areas, there are only fifty medical officers of health), and 25 of the former.

Historical and Cultural Factors.-Scotland's history differs from that of England in many respects, and not least in that the smaller country was never crushed beneath the heel of a conqueror: Scotland had only a partial Roman invasion, no Norman conquest, and no strong Tudor monarchs. Central government (in health matters the Department of Health for Scotland) has never enjoyed in Scotland quite the same amount of respect as is given to its analogue in England, a fact which may further explain the decision of the central authority to retain for itself the power to provide health centres.

The Caledonian zeal for learning is well-known: there were four Scottish universities (each with a medical faculty) when there were still but two in England, and, although England now has some fourteen full universities, it is probably true to say that universities play an appreciably greater part in the life of Scotland than in that of England. Certainly in Edinburgh or Aberdeen one is conscious of being in a university city, whereas in Leeds or Nottingham one is in a city that contains a university. To the Scot it was natural, instead of setting up independent Boards of Governors for teaching hospitals, to think of these hospitals as constituting the cultural centre of each hospital region, and to safeguard the teaching of undergraduates and post-graduates by establishing in each region a Medical Education Committee of which at least one-third of the members must be from the university (a stronger university representation than was accorded in England to the boards of the teaching hospitals). The teaching hospitals of Glasgow, Edinburgh, Aberdeen, and Dundee (which have hitherto provided clinical education for about one-third of the medical students in Britain) are in any case so predominant that to organize a regional hospital service without them would have been a task like producing Hamlet without the Prince of Denmark. Inherent in the different fate of the teaching hospitals was the necessity for the creation in Scotland of a special Hospital Endowments Commission.

Again, a teaching hospital in Scotland has traditionally had as its administrative head a medical superintendent serving as an invaluable link between the medical staff and the board of management. In England, where medical superintendents were a feature of municipal hospitals but not of voluntary hospitals, it was perhaps natural that after 1948 they should tend to disappear except in mental and other special hospitals. In Scotland it was equally natural that they should remain.
From 1915, the Highlands and Islands had an integrated medical and nursing service, based on the general practitioner and the combined, all-purpose, domiciliary nurse, and supplemented latterly by the resources of a hospital and specialist service. In other words, this huge tract of mountains, glens, and sea-lochs, with difficult communications and few inhabitants, had a form of national health service years before the rest of the United Kingdom.

Before the passing of the Act, local authority health functions in Scotland had for nearly a score of years been concentrated in the hands of counties and large burghs, the latter having populations from 20,000 upwards. There was nothing corresponding to the Urban District and Non-County Borough, and consequently the changes of 1948 did not in Scotland result in the appearance of a frustrated group of doctors who, after having been independent chief officers in small population units, found themselves with status and duties little different from those of county assistant medical officers.

Temporal Factors.- The Scottish Act was drafted after some of the tumult that greeted its English analogue had died down. In the light of reason it was possible for the legislators to make a number of small but important alterations in the later Act. For instance, in England the Central Health Services Council had been authorized to advise on services provided under the Act or provided by Local Health Authorities under other Acts, but-presumably through a drafting error-it had been given no power to advise on school health services, which are provided by Local Education Authorities; in the Scottish Act this defect was rectified. - Again, after the passing of the English Act it was felt in some quarters that medical members might in course of time come to dominate Regional Hospital Boards and Hospital Management Committees. As a safeguard, the fourth schedule of the Scottish Act laid it down that at least half the members of each Regional Hospital Board and of each Board of Management must be persons other than medical practitioners.

Yet again, the English Act was drafted during a temporary wave of hostility to local authorities and their services, but by the time the Scottish Act was taking shape, saner forces were at work. Hence the Scottish Act included a specific power of Local Health Authorities to conduct research; and the Scottish Health Services Council has a standing advisory committee on local authority services, a committee which the English counterpart does not yet possess. Similarly, while the Health Services 
Council in England has so far included in its membership only one medical officer of health at a time, the Scottish equivalent has from its inception contained two medical officers of health in a council of smaller total membership.

\section{Effects on General Practice}

The explicit differences between the Acts are least in respect of general practice. Yet there are discrepancies arising not so much from legislation as from use and wont. Whether as a result of the existence of the Highlands and Islands medical service for a third of a century before the commencement of the National Health Service, or as a result of the pre-eminence of the Scottish medical schools in the early decades of the 20th century, the general medical practitioner in Scotland-and especially in the country areas-enjoys a prestige appreciably higher than is common in England. It has to be remembered that the rural family doctor in Scotland often served as assistant medical officer of health for his area, treated his patients in a small hospital, co-operated with a combined health visitor and district nurse, and was in short a complete social and clinical physician.

This fact has, paradoxically, sometimes had the effect of making the Highland tail wag the urban dog. For example, when it was decided that any general practitioner in Scotland could undertake midwifery without special experience or inclusion on a separate list, consideration was undoubtedly given to rural areas where there may be a single practitioner in an extensive tract of country. Whether it was justifiable to apply this criterion to the industrial belt-in which Glasgow alone has a population nearly thrice as numerous as that of the entire Highlands and Islands-is a matter of controversy.

Among local health authority doctors, these Cinderellas of the medical profession, the remark is sometimes made that the Ministry of Health and the Central Health Services Council are in danger of forgetting that there are any doctors other than the staffs of hospitals, while the Department of Health for Scotland and the Scottish Health Services Council tend to be unaware of the existence of any doctors other than general practitioners. That remark (which, although an exaggeration, contains a nucleus of truth) at least indicates the prestige of the family doctor in Scotland.

\section{EfFects on Local Authority Services}

In England a number of progressive authorities have already completed health centres; in Scotland, where local authorities cannot legally provide such centres, one solitary centre (newly opened) is the fruit of the activities of the central government department. Local authorities have no responsibility for ambulance services, and the populations served by most town and county councils are by English standards far too small. Yet, curiously enough, the public health service is in a stronger position in Scotland than in England. Three reasons may be adduced: first, while some of the Scottish units are admittedly too small, it may well be that many of the English administrative counties suffer from the even more serious defect of being too large, and, in particular, that counties asked in 1948 to absorb the health services of populous non-county boroughs and urban districts seem in many cases to be incapable of properly digesting the unduly large meal forced upon them; second, whatever they may have left undone, many Scottish local health authorities have utilized their power-a power not possessed by English authorities-to spend money on co-ordination of services; and third, the Central Department in Scotland has from the beginning been less disposed to ignore prevention of disease than was its English counterpart. There is, for example, no English official publication to correspond to the 1951 Report entitled "What Local Authorities can do to promote Health and prevent Disease": this report of the Scottish Health Services Council urged local authorities to "play a leading part in the campaign to improve physical and mental health", invited medical officers of health to study accidents and to apply epidemiological methods to their control, indicated that "the educative influence of a progressive local authority can do much" to prevent deaths from respiratory disease, stressed the economic value of preventive services, urged medical officers of health to study social and occupational factors in disease, called for an extension of after-care services, asked local authorities to give attention to reduction of disease in the elderly, called for the promotion of mental health, stressed that "the health visitor is an educator of supreme importance", and asked local authorities to remember the new powers they had been given to promote research. Such a document, issued with the weight and authority of a central council, could hardly fail to stimulate at least some local authorities and to remove the formerly prevalent misconception that the sphere of these authorities had contracted instead of expanding.

A further instance of the attitude of the Central Department to local health authority services may be seen in a speech made by the Secretary of the Department of Health for Scotland on April 24, 1952 (Health Bulletin, Department of Health for Scotland, 1952, 10, 43): here Sir George Henderson publicly stated that local authorities should investigate 
diseases of maturity, that the medical officer of health should be as concerned with old people as with pre-school children, and that he

need no longer mainly concern himself with infectious diseases and sanitation; in fact, he is now a sociologist with clinical insight.

Further examples of this more enlightened attitude on the part of the Department are not difficult to find. In Scotland, Rutherglen was allowed to start a geriatric clinic, Rutherglen and Aberdeen instituted chiropody services for pensioners, Aberdeen set up a night-nursing service as an extension of the ordinary day service, and Greenock and Paisley offered B.C.G. immunization to school-leavers; in England Salford's proposals for a chiropody service and Stoke-on-Trent's scheme for B.C.G. immunization were disapproved by the Ministry of Health.

The above examples should not be taken as implying that local health authority services are in a healthy state in Scotland. The same financial disparities and the same serious quantitative and qualitative shortages of local authority medical, dental, and health visiting staff exist in Scotland as in England; but the smaller country gives much more evidence of being aware of the dangers of the situation and of being concerned to remove them if it is still possible to do so.

\section{EfFects on Hospital Services}

The differences are greatest in the hospital services, the main points being perhaps the smaller populations served by three of the five Scottish hospital regions, the absence of any division in Scotland into regional boards for non-teaching hospitals and boards of governors of teaching hospitals, and the continued existence in Scotland of the medical superintendent.

These points are clearly connected, and it is extremely hard to obtain objective evidence of the advantages or disadvantages of any one point. There appears to be a fairly general impression that the North-Eastern and Eastern Regions function more smoothly and efficiently than do those serving appreciably larger populations: waiting lists in these regions of 400,000 and 500,000 persons are certainly much smaller than would be accounted for merely by variations in the gross populations served; and the standard of co-operation with other branches of the Service is very high in the "small" units.

As for the medical superintendent, many people in England seem to regard him as unnecessary, whereas most people in Scotland consider him to be an essential link between the staff and the board of management. It is certainly very convenient-to put it no higher-for a consultant in charge of a ward to be able to discuss drugs, operating tables, lighting of a theatre, or plans for a new ward with someone who has medical knowledge but whose primary interest is administration; and it is equally convenient for a board of management to have as its chief adviser an officer with technical knowledge but without any particular axe to grind. On the other hand, in the British Civil Service a system has evolved whereby its highest posts are filled by persons without technical knowledge, and it might conceivably be thought logical to seek to extend this system to hospitals. At any rate, if some of the other variables can be studied and eliminated, it should not be beyond human ability to assess the merits or demerits of the superintendent system by impartial comparison.

In the years of over-heated discussion and impassioned argument that immediately preceded the passing of the Health Acts it was obvious that a substantial section of opinion in England felt that, if the teaching hospitals were brought within the framework of the regional hospital administration, there would be a danger of levelling down, so that these hospitals would be hindered in their research work and in their standard of service through lack of money and staff. It is, therefore, particularly interesting to compare the effects of the English dichotomy of teaching and non-teaching hospitals and of the Scottish policy of unification. On balance, these effects appear to favour the Scottish method. First, there is less reluctance in Scotland on the part of a young consultant to accept a post at the periphery of a region: in England the doctor who takes such a post tends to feel that he has completely lost contact with the men whom he regards as the leaders in his particular specialty. Possibly arising from this fact, the standard of specialist treatment appears to be higher in Scotland than in England: in the main teaching hospitals the standard is probably not dissimilar in the two countries, but as one moves from teaching to non-teaching hospital the decline is far sharper in England than in Scotland. Again, facilities for teaching students tend to be better under the Scottish system: in England the teaching hospitals must use the material actually available to them, but in Scotland the interesting or instructive case can be moved from the non-teaching peripheral hospital to the teaching hospital at the centre. Not least, there is in the larger country a very real danger of the developiment of two classes of hospital, whereas in Scotland this danger is much less serious. As for staffing and facilities for research, recent official statistics show that the teaching hospitals of England are much more lavishly staffed in all their 
departments than the Scottish teaching hospitals, but the staffs of non-teaching hospitals in England complain bitterly of being chronically overworked and of having no time for research. One gets the impression that, while the total amount per head of population is about the same in the two countries, in England the first priority is the maintenance or improvement of the high standards of the teaching hospitals, while in Scotland the emphasis is placed on raising the peripheral hospitals to the level of the teaching centres. It may be, of course, that the Scottish policy is economically unwise, some units being probably too small to be made efficient at reasonable cost.

It is hard to evaluate the amount and quality of research work undertaken in the hospitals of the two countries. In some of the newer branches of medical science (e.g. geriatrics) more research seems to be conducted south of the Cheviots, whereas in some of the older branches (e.g. obstetrics) this is certainly not so.

If we attempt to judge by the standard of the average hospital care available to a person who falls sick in either country or by the standard of the average time that such a person has to remain on a waiting list, such information as is available appears to favour Scotland. The outstanding feature of the Scottish system, however, is probably not the bringing of teaching and non-teaching hospitals under unified control, and not even the existence of the medical superintendent, but the relative smallness of population in three of the five Scottish hospital regions. These less populous regions function remarkably smoothly, co-operate well with other branches of the Health Service, and do not appear to encounter many of the difficulties found elsewhere: it is perhaps legitimate to infer from these facts that to ask a group of individuals to act as the members and officials of a hospital board for a population of several million persons is to impose on them a task beyond the capacities of normal human beings, and to create a Frankenstein's monster which no one can control.

•

The differences in the National Health Services of England and Scotland are least in respect of the general practitioner service, considerable in respect of local health authority work, and greatest in respect of hospitals. Some of the main peculiarities of the Scottish set-up are:

(i) three of the five hospital regions serve small populations;

(ii) teaching hospitals are controlled by the Regional Boards;

(iii) medical superintendents are the rule, not the exception;

(iv) the ambulance service is delegated by the Secretary of State to hospital boards;

(v) provision of health centres is a matter for the central government department;

(vi) local authorities in general serve smaller populations;

(vii) no local authorities lost health functions in 1948;

(viii) local health authorities have a specific power to undertake research;

(ix) the areas of local executive councils are noto coterminous with those of local health? authorities.

Historical and geographical reasons for some differences are given, and a few of the effects are discussed.

\section{REFERENCE}

Henderson, G. (1952). Health Bulletin, Dept. of Health for Scotland, 